\title{
D209 非構造格子を用いたマイクロポンプ内流れの有限要素解析
}

\section{Finite Element Analysis of Flow in Micro Pump using Unstructured Grid}

\author{
○正 松本純一 (産総研) 正 高田尚樹 (産総研) 正 松本壮平 (産総研) \\ 正 市川直樹 (産総研) Sven Heisig(産総研) 三原孝士 (オリンパス・未来創研)
}

\begin{abstract}
Junichi Matsumoto, Natl Inst Adv Ind Sci \& Technol (AIST), 1-2-1 Namiki, Tsukuba
Naoki Takada, Natl Inst Adv Ind Sci \& Technol (AIST), 1-2-1 Namiki, Tsukuba

Sohei Matsumoto, Natl Inst Adv Ind Sci \& Technol (AIST), 1-2-1 Namiki, Tsukuba

Naoki Ichikawa, Natl Inst Adv Ind Sci \& Technol (AIST), 1-2-1 Namiki, Tsukuba

Sven Heisig, $\quad$ Natl Inst Adv Ind Sci \& Technol (AIST), 1-2-1 Namiki, Tsukuba

Takashi Mihara, Olympus Corp., Shinjuku Monolith 2-3-1 Nishi-Shinjuku, Shinjuku
\end{abstract}

\begin{abstract}
As for the fluid problems of MEMS (Micro Electro Mechanical Systems) such as micro-inkjets and micropumps, there are many cases of incompressible and compressible flow problems. In this paper, orthogonal basis bubble function finite element method is proposed for compressible viscous flow. As for the numerical examples, analyses of flow in a micro-pump are investigated with respect to the numerical accuracy and stability of orthogonal basis bubble function element stabilization method. By applying our scheme to compressible flow problems in micro-pumps under some collaboration with experimental researchers, it is confirmed that our method is very powerful in the micro scale simulations.
\end{abstract}

Key Words : MEMS, Micro-pump, Compressible Viscous Flow, Finite Element Method, Orthogonal Basis Bubble Function Element

\section{1.は じめに}

本研究は，マイクロ流体デバイスにおける機械的な駆 動部を全く持たない気体ポンプ（メカレスポンプ）の設 計・開発のための流体解析を行っている. 三角形, 四面体 の非構造格子で分割が可能な直交基底気泡関数要素 ${ }^{(1)} に$ よる安定化有限要素法 ${ }^{(2),(3)}$ (直交基底気泡関数有限要素 法 $^{(4)}$ ) を圧縮性粘性流れに適用し, マイクロポンプ内の 実際形状での流れ解析を実行した. 3 次元実際形状での 解析では, 流路幅のスケール比的 100 倍, 温度差約 1000 度といった条件での解析を行い，2 次元モデルを用いた ノズル部の解析にて流体ダイオードの効率とマイクロポ ンプ内の流れの性質について検討を行った.

\section{2. 直交基底気泡関数有限要素法を用いた数值解析}

本研究では, マイクロポンプ内の実際形状での流れ解 析を行うにあたり, 計算の効率・精度が良く, かつ数值 安定性に優れた直交基底気泡関数有限要素法 ${ }^{(1)}$ を圧縮性 粘性流体の方程式に適用した ${ }^{(4)}$. 気泡関数要素 (Bubble function element) は三角形，四面体要素の非構造格子に 適用が可能であり, Fig.1に示すように, 三角形, 四面体 の頂点と重心点に自由度をもつ要素である. 直交基底気 泡関数有限要素法を適用した有限要素方程式に対して,

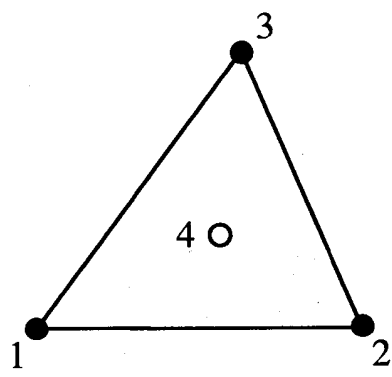

(a) Two dimensional

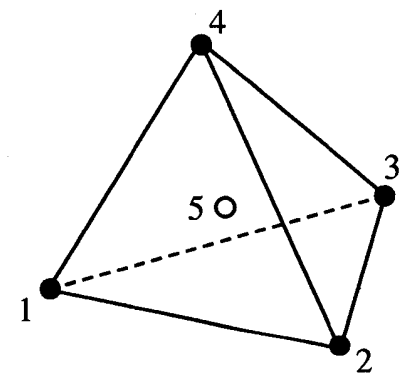

(b) Three dimensional
Fig. 1 Bubble function element

時間方向の計算を安定に行うために時間方向の 2 次精度 を考慮した陰的解法 ${ }^{(5)}$ を採用した。

\section{3 次元マイクロポンプ内の流れ解析}

気体用メカレスポンプの 3 次元モデル数值シミュレー ションを行う。このデバイスは, ポンプの役割をはたす駆 動力として温度変化を気体に与え, その密度変化（膨張 収縮）を用いる. 気体の温度変化を与えるチャンバーに は一方向に流れやすくするノズルが取り付けてあり, 正 味の流量として一方向へ気体を送り出すことができるこ とが想定されている. ポンプ内の数值シミュレーション を行なうにあたり, 装置の仕組みからして密度変化（膨 
張）の考慮は重要な要因であるので，圧樎性粘性流体の 数值解析が不可欠となる. Fig.2 4に流速（粒子）と圧力 コンタの計算結果を示す．この計算は，チャンバの上部 （各計算結果の中央の円筒部分）に，境界条件として 20 度から 1000 度といった非常の大きな温度差を不連続なス テップ関数の波形分布で与えている．温度波形として 20 ${ }^{\circ} \mathrm{C} \sim 500{ }^{\circ} \mathrm{C}$ のテップ関数 (Case1), $20^{\circ} \mathrm{C} \sim 1000{ }^{\circ} \mathrm{C}$ のス テップ関数 (Case2), $20^{\circ} \mathrm{C} \sim 500{ }^{\circ} \mathrm{C}$ のサイン関数 (Case3) の 3 ケースの非定常計算を $30 \mu\left(3 \times 10^{-5}\right)$ 秒まで行なっ た. 直交基底気泡関数有限要素法を用いた数值解法では，

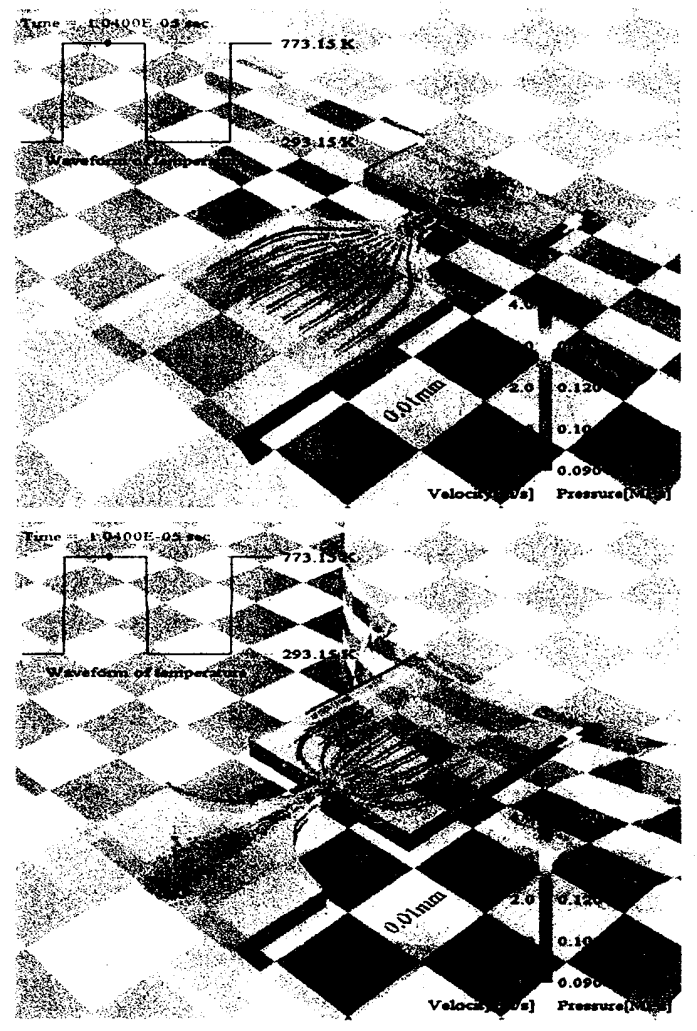

Fig. 2 The computational result of Case 1

境界条件として 20 度から 1000 度といった非常の大きな 温度差を不連続なステップ関数の波形分布で与えている 問題に対しても安定に計算が実行できている.

\section{2 次元気体ポンプ内流れ解析による流体ダイオード 効业の検討と流れ現象の把握}

流体ダイオード効率と流れ現象の把握を目的として， Fig.5に示すノズル形状について良好な流体ダイオード 効率が得られるかについて検討を行った．流体ダイオー ド効率の評価にあたり，圧力差 $\Delta p$ の与え方および流体 ダイオード効率の算出は Fig.5 の計算式に従っている. 雾囲気温度 $T=300 \mathrm{~K}$, 気体は窒素を仮定した. Fig.6 に圧 力差 $0.001 \mathrm{MPa}($ Case 1$), 0.02 \mathrm{MPa}$ (Case2), $0.04 \mathrm{MPa}$ (Case3),

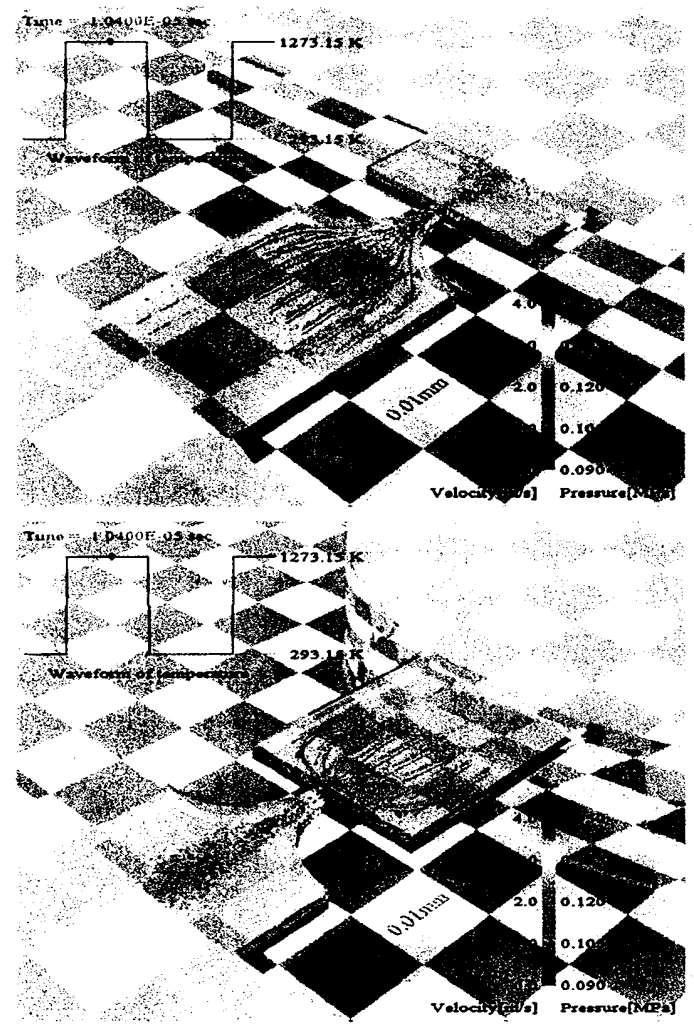

Fig. 3 The computational result of Case2

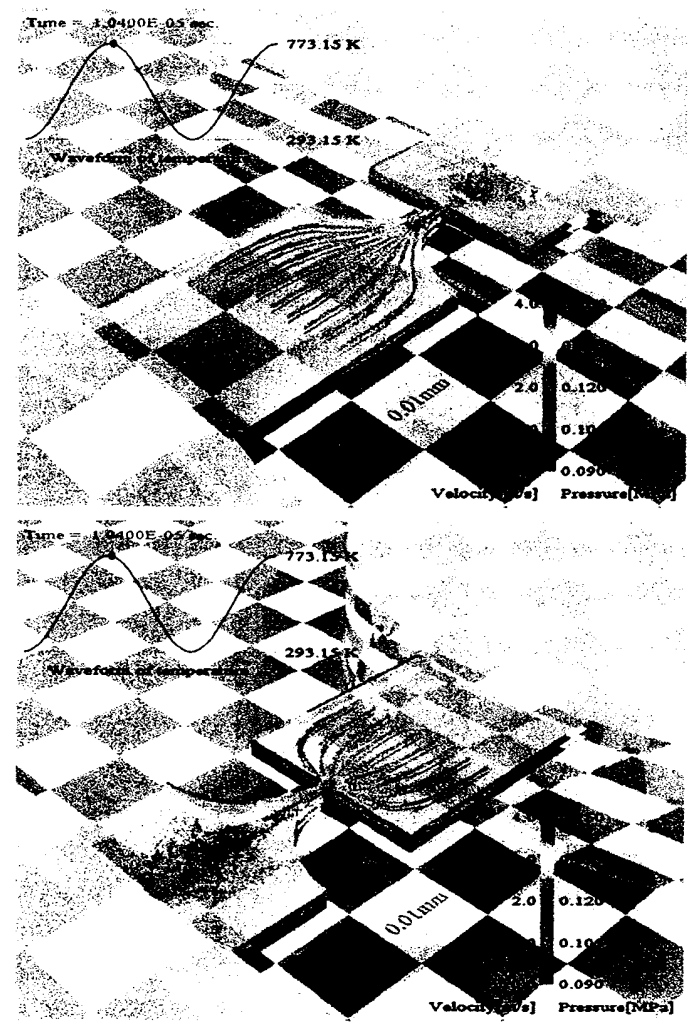

Fig. 4 The computational result of Case 3 
$0.05 \mathrm{MPa}$ (Case4) とした場合の時間における質量流量 (Mass flow) の変化と流体ダイオード効率の計算結果を, Fig.7〜Fig.10 に Case1〜Case4 の流速ベクトルを示す. Case1 では, 順方向 (Forward flow), 逆方向 (Backward

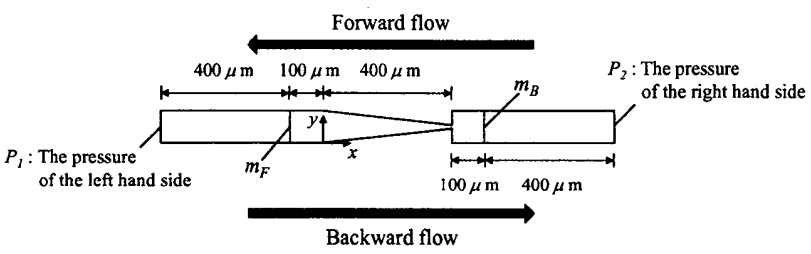

$$
\begin{gathered}
m_{F}=-\int_{L} \rho_{F} u_{F} d L \times H \quad m_{B}=\int_{L} \rho_{B} u_{B} d L \times H \\
M_{F}=\frac{\int_{t_{0}}^{t_{f}} m_{F} d t}{t_{f}-t_{0}} \quad M_{B}=\frac{\int_{t_{0}}^{t_{f}} m_{B} d t}{t_{f}-t_{0}} \\
H=20 \mu \mathrm{m}, t_{0}=150 \mu \mathrm{sec} ., t_{f}=200 \mu \mathrm{sec} .
\end{gathered}
$$

The efficiency of the fluidic diode $=\frac{M_{F}-M_{B}}{M_{F}+M_{B}} \times 100(\%)$

Fig. 5 Computational model

flow) 共にノズル内中央部での直線的な流れになってい る. Case2 では，順方向では蛇行した流れ，逆方向では 偏って湾曲・蛇行する流れになっている. Case3 では, 順 方向では蛇行した流れ，逆方向ではノズル最小幅の部分 から噴き出した流れが乱れ小さくではあるが質量流量が 上下動する流れになっている. Case4 では，順方向では 蛇行した流れ, 逆方向ではノズル最小幅の部分から噴き 出した流れが大きく乱れた質量流量が大きく上下動する 流れ（逆方向の質量流量が順方向の質量流量よりも一時 的に大きくなる場合が生じるような流れ）になっている. $0.001 \mathrm{MPa} \sim 0.055 \mathrm{MPa}$ の差力圧において，さらに詳細な 計算を行った時の圧力差と流体ダイオード効率が Fig.11 である. Fig.11 の計算結果では, 「中央部での直線的な流 れ」から「偏って湾曲・蛇行する流れ」に遷移する差力圧 は 0.002 0.003MPa の間であり,「偏って湾曲・蛇行する 流れ」から「ノズル最小幅の部分から噴き出した流れが 乱れ小さくではあるが質量流量が上下動する流れ」に遷 移する差力圧は 0.032〜0.033MPa の間であり,「ノズル最 小幅の部分から噴き出した流れが乱れ小さくではあるが 質量流量が上下動する流れ」から「ノズル最小幅の部分 から噴き出した流れが大きく乱れた質量流量が大きく上 下動する流れ」に遷移する差力圧は 0.041 0.042MPa の 間であった.この計算結果により，Fig.5のノズル形状に ついて，適切な圧力差の設定により良好な流体ダイオー ド効率を得ることができ, 圧力差が $0.002 \mathrm{MPa}$ より大き く0.042MPa 未満とした場合に高い流体ダイオード効率 を達成できることがわかった。
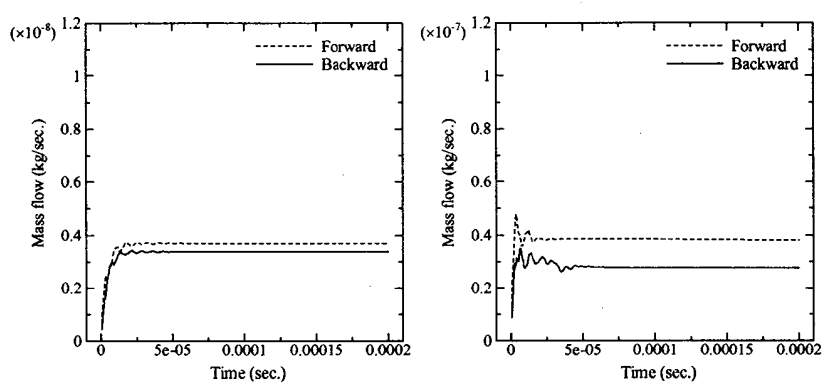

Case1 (Efficiency $4.37 \%$ )

Case2 (Efficiency $16.26 \%$ )
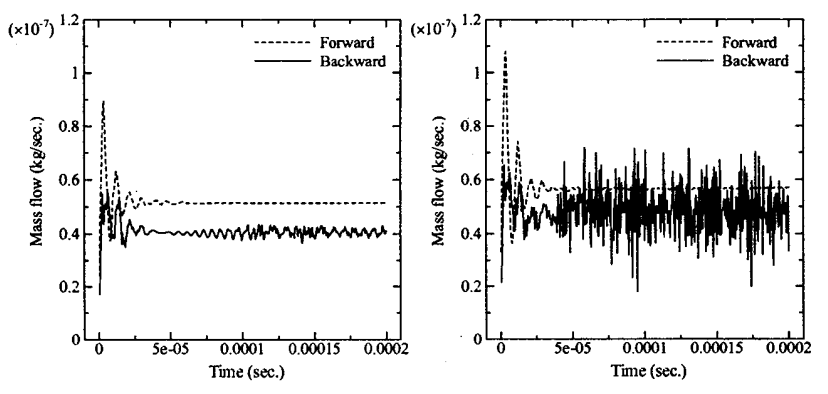

Case3 (Efficiency $11.68 \%$ ) Case4 (Efficiency $8.23 \%$ )

Fig. 6 The efficiency of the fluidic diode

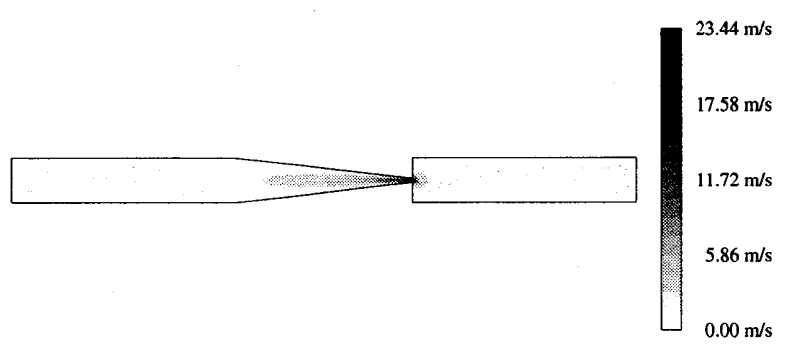

(a) Forward flow $(\Longleftarrow)$

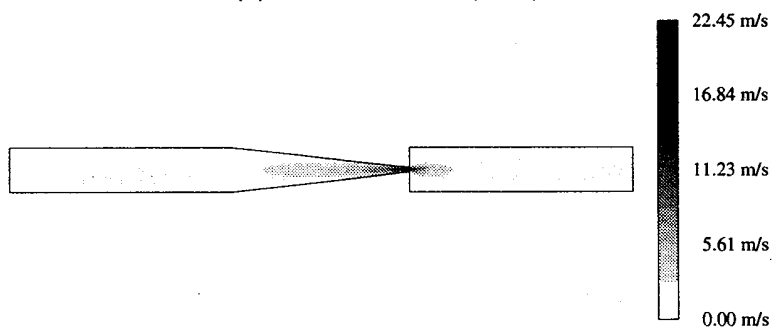

(b) Backward flow ( $\Longrightarrow$ )

Fig. 7 The velocity vectors of case $(\Delta p=0.001 \mathrm{MPa})$

5. おわりに

本研究では, 圧縮性粘性流れによる直交基底気泡関数 有限要素法を用いて, 実際モデルにおける 2 次元， 3 次 元のマイクロポンプ内流れ解析を行った. 3 次元実際形 状での解析では, 流路幅のスケール比約 100 倍, 温度差 約 1000 度といった条件での解析を行い，2次元モデルを 用いたノズル部の解析にて流体ダイオードの効率の検討 と流れ現象の把握を行った。 


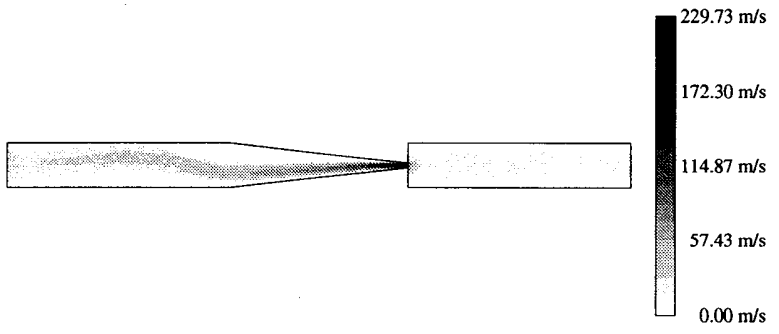

(a) Forward flow $(\Longleftarrow)$

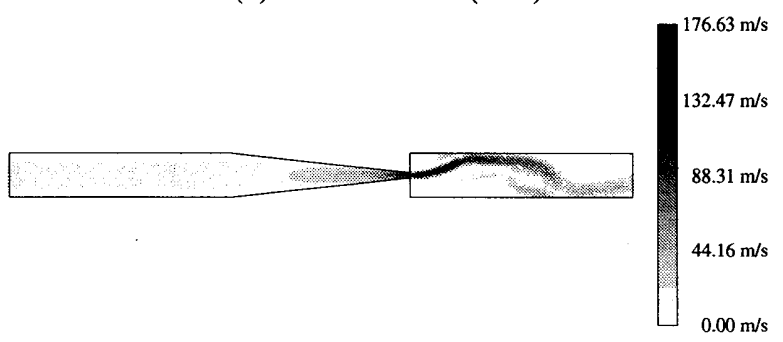

(b) Backward flow $(\Longrightarrow)$

Fig. 8 The velocity vectors of case $2(\Delta p=0.02 \mathrm{MPa})$

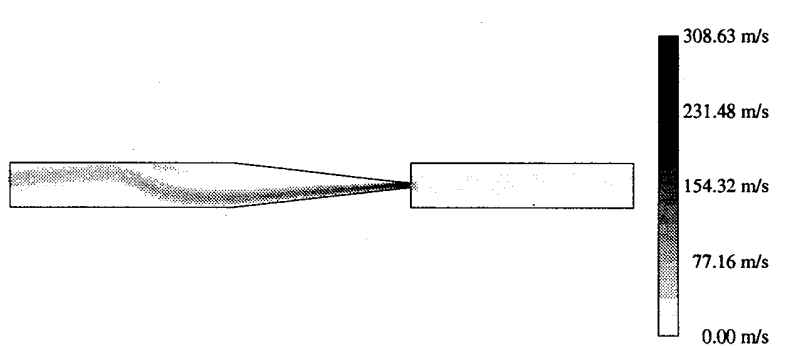

(a) Forward flow (

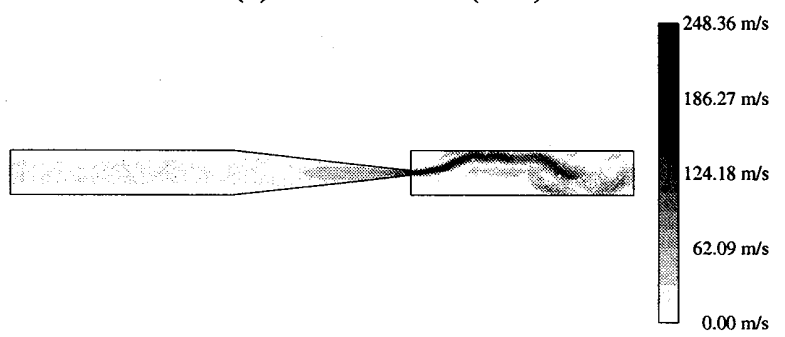

(b) Backward flow $(\Longrightarrow)$

Fig. 9 The velocity vectors of case $3(\Delta p=0.04 \mathrm{MPa})$

\section{文献}

(1) Matsumoto,J. : A relationship between stabilized FEM and bubble function element stabilization method with orthogonal basis for incompressible flows, Journal of Applied Mechanics JSCE, Vol.8, pp.233-242, 2005.

(2) Hauke,G., and Hughes,T.J.R. : A comparative study of different sets of variables for solving compressible and incompressible flows, Comput. Methods Appl. Mech. Engng., Vol.153, pp.1-44, 1998.

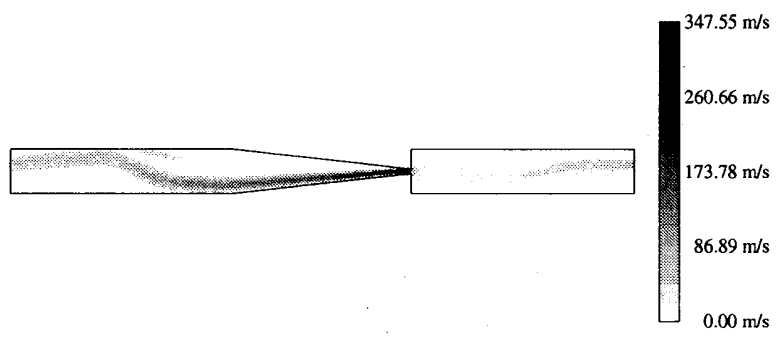

(a) Forward flow $(\Longleftarrow)$

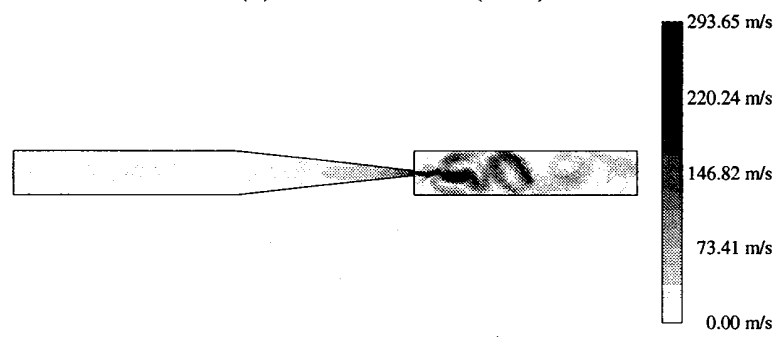

(b) Backward flow ( $\Longrightarrow$ )

Fig. 10 The velocity vectors of case $4(\Delta p=0.05 \mathrm{MPa})$

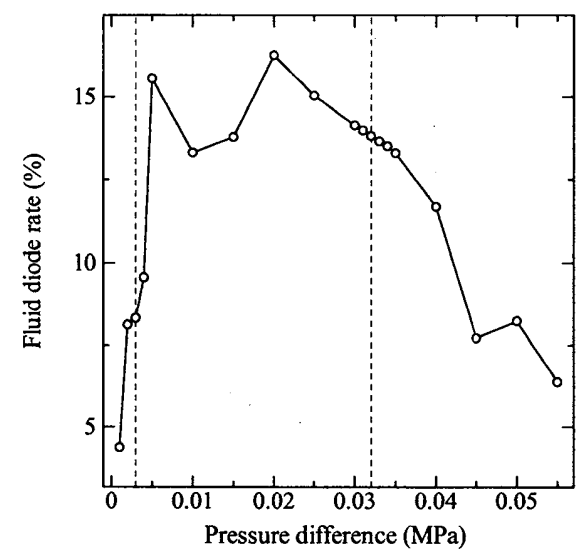

Fig. $11 \Delta p$ and the efficiency of the fluidic diode

(3) Tezduyar,T.E., and Senga,M. : Stabilization and shock-capturing parameters in SUPG formulation of compressible flows, Comput. Methods Appl. Mech. Engng., Vol.195, pp.1621-1632, 2006.

(4) Matsumoto,J., et al. : Compressible viscous flow analysis for MEMS using orthogonal basis bubble function finite element method, The 3rd Asian-Pacific Congress on Computational Mechanics (APCOM'07EPMESC XI), pp.356 (Proceedings in CD-ROM), 2007.

(5) Simo,J.C., and Armero,F. : Unconditional stability and long-term behaver of transient algorithms for the incompressible Navier-Stokes and Euler Equations, Comput. Methods Appl. Mech. Engng., Vol.111, pp.111-154, 1994. 